\title{
Information Technology and Sustained Competitive Advantage: A Resource-Based Analysis
}

By: Francisco J. Mata, William L. Fuerst, and Jay B. Barney

Page 487

A topic of great interest to both researchers and practitioners involves whether information technology (IT) can serve as a source of sustained competitive advantage, and, if so, exactly how this is accomplished. In this article, the authors explore this issue through the adoption of a resourcebased view of the firm.

The resource-based view of the firm is grounded on two main assertions: that the resources and capabilities possessed by competing firms may differ and that these differences may be long lasting. Advocates of this theory posit that firms' resources and capabilities can be the foundation of a sustained competitive advantage when one or more of the following conditions apply: (1) a firm is uniquely positioned (being at the "right place at the right time") to acquire the resources/capabilities, (2) the resources/capabilities can only be developed over long periods of time, (3) the resources/capabilities represent taken-for-granted, tacit, unspoken attributes of the firm, (4) the competitive advantage arises through a large number of small decisions and actions rather than through a few large decisions and actions, and (5) the resources/capabilities are socially complex (i.e., such as a firm's culture, reputation, or trustworthiness).

It is then maintained that five specific attributes of IT might serve as possible sources of sustained competitive advantage: customer switching costs, access to capital, proprietary technology, technical IT skills, and managerial IT skills. Through crisp and highly readable arguments, the authors conclude that of these five attributes only IT managerial skills is likely to be a source of sustained competitive advantage. 